\title{
Analysis of the reasons and prospect for the abandonment of new energy power in China
}

\author{
ZHOU Qiang ${ }^{1,2, a}$,WANG Ning-bo ${ }^{1,2}$, SHEN Chen-yun ${ }^{3}$,ZHAO Long ${ }^{1,2}$,WANG \\ Ding-mei $i^{1,2}, Z$ ZHANG Jian-mei ${ }^{1,2}$ \\ ${ }^{1}$ Wind Power Technology Center of Gansu Electric Power Company , China \\ ${ }^{2}$ Gansu Wind Power Engineering Technology Center, China \\ ${ }^{3}$ State Grid Gansu electric power company Gannan power supply company, China \\ aeezhouqiang@163.com
}

\begin{abstract}
Keywords: New energy distribution; abandoned new energy power; wind power; photovoltaic power;new energy prospect.
\end{abstract}

Abstract. With China's economy goes into the new normal background, the problem of abandoning new energy power is becoming increasingly prominent. It comprehensively summarizes the development process of new energy from 2004 to 2014, and summarizes the current status of new energy development in China. Based on the authority data released by the National Energy Bureau, it calculates the average rate of abandoned wind rate and the total disposable wind power from 2011 to 2015 in China, and analyses the prospects of China's new energy development in short-term and long-term. Finally, the four major factors that affect the development of new energy in China under the new normal background are given.

\section{Introduction}

The rapid development of China's new energy started in 2008, China's new energy power installed capacity continues to rise, showing a "blowout" situation, there have eight million kilowatts new energy base approved to be constructed, it opens a large-scale, high proportion, centralized development, long-distance transmission of new development model, China's wind power installed capacity increases from $12002 \mathrm{MW}$ in 2008 to $114609 \mathrm{MW}$ in the end of 2014, the photovoltaic power installed capacity increases from $145 \mathrm{MW}$ in 2008 to $28050 \mathrm{MW}$ in the end of 2014 , it creates a miracle in the world history of the development of the new energy. But at the same time, such as wind power taken off from grid, power grid stability problems , abandon new energy power are becoming severe problems. With China's economy goes into the new normal background, what the future of this "blowout" mode of development is be analyzed in this paper.

\section{Development of new energy in China}

China's total new energy power installed capacity and globe share from 2004 to 2015 shows in Fig. 1.

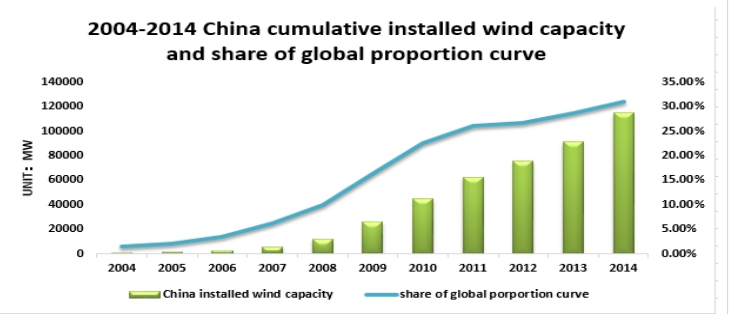

(a)wind power

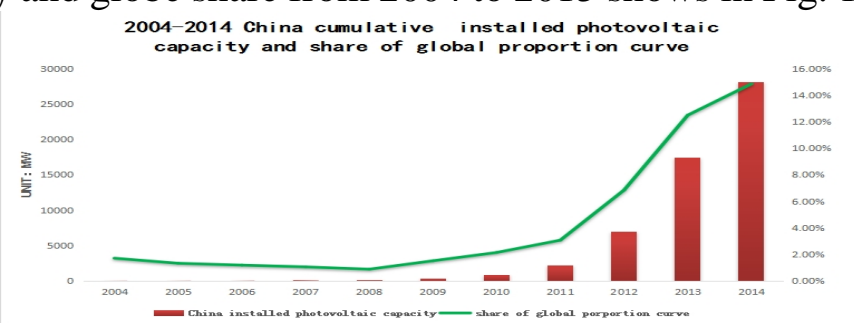

(b)photovoltaic power

Fig. 1 China's total new energy power installed capacity and globe share from 2004 to $2015^{[1,2,4,6-9]}$

Fig. 1 shows China's wind power installed capacity increases from 743MW in 2004 to $114609 \mathrm{MW}$ in the end of 2014,the photovoltaic power installed capacity increases from $64 \mathrm{MW}$ in 2008 to $28050 \mathrm{MW}$ in the end of 2014. 


\section{Distribution of new energy power in China}

By June 2015, the wind power cumulative installed capacity in China is $124710 \mathrm{MW}$, the growth is $27.6 \%$ compared to the same period of 2014, In the first half of 2015 the wind power capacity connected to grid is $9160 \mathrm{MW}$, it shows in Fig. 2.The photoelectric power installed capacity reaches to $35780 \mathrm{MW}$, the specific situation shows in Fig. 3.

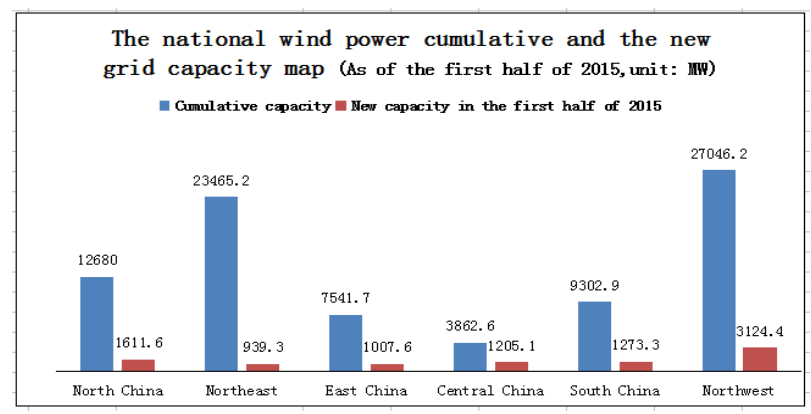

(a)region

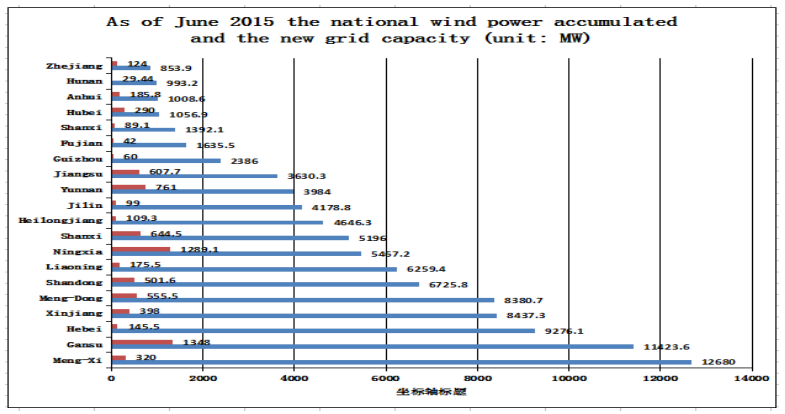

(b)province

Fig. 2 Cumulative wind power capacity in regions and provinces of China in $2015^{[1,2,4,6-9]}$

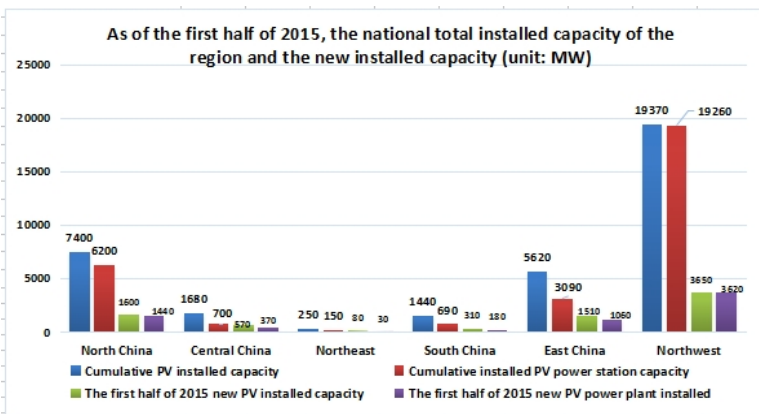

(a)region

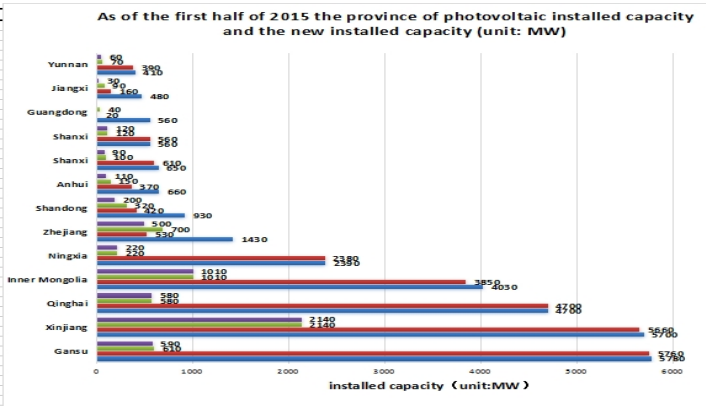

(b)province

Fig. 3 Cumulative photoelectric power installed capacity and new installed capacity in region and provinces of China in $2015^{[3,5]}$

\section{Abandoned wind power in China}

Wind power connected to gird and abandoned wind power in China from 2011 to 2015 shows in Fig.4,

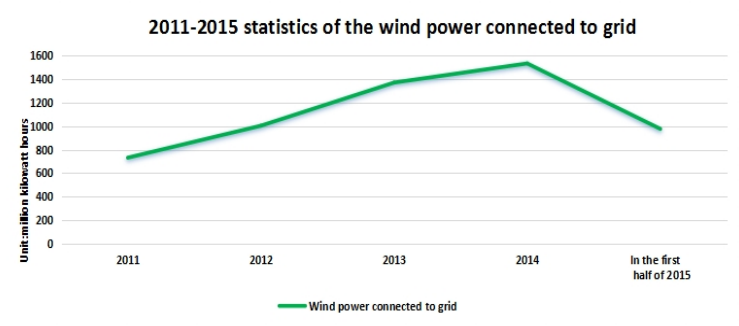

(a)wind power connected to grid

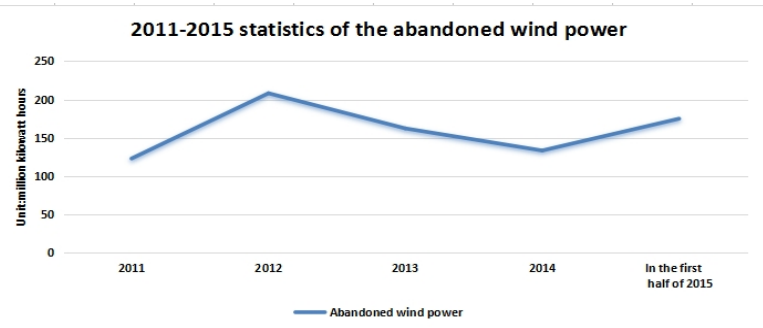

(b)abandoned wind power

Fig. 4 Wind power connected to gird and abandoned wind power in China from 2011 to 2015 

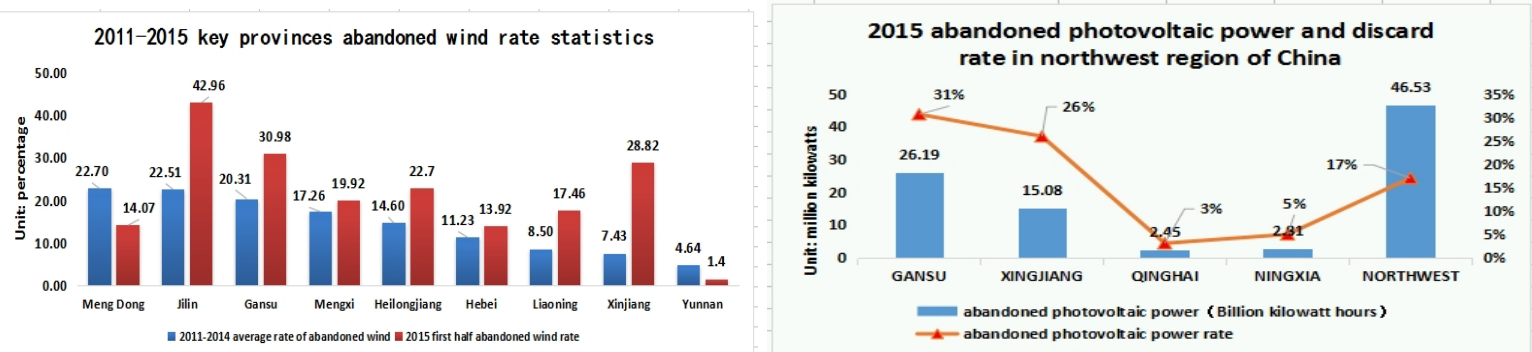

Fig. 5 Abandoned wind power rate of China from 2011 to 2015. Fig. 6 Abandoned photovoltaic power and discard rate of China in $2015^{[3,5]}$

Fig 5 shows the top three provinces of the average abandoned wind power rate is eastern Inner Mongolia( 22.7\%), Jilin(22.51\%), Gansu(20.81\%),Fig 6 shows that the abandoned photoelectric power rate in northwest region is very high, the averge rate is $17 \%$ and the number in Gansu is $31 \%$.

\section{Reasons for the abandonment of the new energy in China}

The new energy development in China shows a trend of a "Contradictory dilemma ". On one side is that the new energy development with unprecedented speed which constantly refreshes the installed capacity. The other side is that many provinces encounter with high rates of abandoned new energy power, China hit the cold reality of new energy efficiency is not high and seriously waste of resources. The main reasons:

(1) China's new energy power surplus is an institutional and structural surplus, which is a relative surplus; In the past few years, a plurality of large-scale centralized new energy bases have been approved to construct, these bases locate in undeveloped, weak grid structure regions, when these areas the new energy installed capacity comes to a certain size, which exceed the local absorptive capacity will cause a surplus of new energy power.

(2)Aggressive style development of new energy makes the new energy installed capacity continues to "blowout", the construction of power grid and supporting policies is difficult to follow, resulting in new energy power hard to send out by grid.

(3)National and local planning coordination is not uniform, which exacerbates new energy consumptive problems. National authorities take over the right for approving wind farm which exceeds 50WM , below 50WM is approved by local government, but due to local governments for their own interests, many wind farms are split into $49.5 \mathrm{WM}$ to build, which makes total wind power installed capacity in many provinces exceed the installed capacity approved by nationa authorities. (4) In the past ten years, due to the absence of the full electric power integrated planning, which results in electric power industry was not able to realize the coordinated development, making power installed capacity increased with ultra high speed, greatly beyond the capacity of power grid configuration, this is also an important factor which makes new energy surplus.

(5) The economy of China enters the new normal from the rapid growth, China's economic downward and the electricity load growth slowdown squeeze the new energy power consumptive space, which will make new energy consumptive pressure increase.

\section{Analysis of new energy prospects and challenges}

(1)Short term development prospects

From Fig 1 to Fig 6 shows that China's new energy development show the high loading capacity, high installed growth, high abandoned rate, high subsidies and low utilization rate since 2011, which is the main features of China's new energy industry.In the short term, China's new energy development path is full of thorns. In terms of internal factors: after the rapid development from 2008 to 2015, China's new energy industry has entered a stage of policy effectiveness "highlights period" and "digestion period", therefore, the installed capacity will continue to grow at high speed. In external aspects: due to the current economy of China changes from the rapid growth into the slow 
growth, the second industry and high energy consuming industry goes into the industry "winter", the total electricity consumption continues to decline,so in the short term, new energy consumptive difficult in a period of time will still exist, it is difficult to effectively resolve.

(2)Long-term development prospects

The development of new energy of China in future mainly will be decided by China's future economic development mode, energy saving and emission reduction goals and the 13th Five-year energy Plan and regional collaborative development.

First: Innovation, coordination, green, open and shared economic development concept requires that we must vigorously develop new energy sources.

Second:The global commitments of energy saving and emission reduction must be based on the full implementation of the new energy strategy to achieve.

Third: only the development of new energy to crack the plight of the governance environment and energy crisis.

Fourth: The development of new energy brings new opportunities for the transformation and development in Western region of China.

\section{Contradictions needed to be resolved}

In summary, in order to achieve the healthy and sustainable development of China's new energy power, which need to deal with the following four major contradictions:

(1)The contradiction between the consumptive problem caused by growing installed capacity of new energy with the insufficient consumptive ability of power grid due to the economic downward.

(2)The contradiction between the high abandoned new energy power rate and the thermal power installed capacity continued to increase with the incremental slowdown in power market.

(3) The contradiction between the installed new energy capacity in undeveloped region in China continued to increase with the shortage of power network transmission channel and insufficient transportation capacity.

(4) The contradiction between the vigorous development of new energy industry and the imperfection of the current China's new energy policy.

\section{Conclusions}

Therefore, the phenomenon of high proportion of abandoned new energy power in China is due to that the energy resources and energy market reversed, which makes the new energy power is difficult to consume,so it is a relative surplus, In the short term, the development of new energy in China will still have a lot of problems, the phenomenon of high abandoned new energy in China will still exist. In the long term, the development of clean energy still will be the focus of China's energy strategy, new energy installed capacity in China will continue to maintain high growth momentum.

\section{Acknowledgements}

This work is supported by National High Technology Research and Development Program(No. 2011AA05A104); State Grid Corporation of China Program(No. 522727160002);Gansu Provincial Power Company of Science and Technology Program(No. 52272714000W)

\section{References}

[1] National Federation of New Energy Chamber of Commerce, the new global energy development report 2015[S], 2015

[2] 2015 China wind power installed capacity statistics [R], China Renewable Energy Association , 2015

[3] 2015 Statistics of photovoltaic power generation in China[R], National Energy Board.2015 
[4] 2015 China wind power operation[R], National Energy Board.2015

[5] 2015 Run power industry profiles in China[R], National Energy Board. 2015

[6] 2014 Wind power industry to monitor the situation[R], National Energy Board,2014

[7] 2013 Wind power industry to monitor the situation[R], the National Energy Board,2013

[8] 2012 Key areas of wind power consumptive regulatory reporting[R], the State Electricity Regulatory Commission,2012.

[9] 2011 Key areas of wind power consumptive regulatory reporting[R], the State Electricity Regulatory Commission,2011 